\title{
White coat hypertension: improving the patient-health care practitioner relationship
}

This article was published in the following Dove Press journal:

Psychology Research and Behavior Management

2 May 2015

Number of times this article has been viewed

\section{Briana Cobos \\ Kelly Haskard-Zolnierek \\ Krista Howard}

Department of Psychology, Texas State University, San Marcos, TX, USA

\begin{abstract}
White coat hypertension is characterized by the variability of a patient's blood pressure measurements between the physician's office and the patient's home environment. A patient with white coat hypertension has high blood pressure levels in the physician's office and normal blood pressure levels in their typical environment. This condition is likely caused by the patient's anxiety within the physician's office and in the presence of the physician. Research has shown that improving the relationship between a patient and their health care provider can decrease the patient's anxiety, with the implication of decreasing the patient's likelihood of demonstrating white coat hypertension. This review provides an overview of the previous literature regarding white coat hypertension, its prevalence, and the consequences for those who develop persistent hypertension. Furthermore, this review discusses the implications of improving patient and health care provider interactions through effective communication, empathy, and trust, as well as the implications for future research studies in improving the patient and health care provider's relationship.
\end{abstract}

Keywords: white coat hypertension, anxiety, health care professional-patient relationship, physician-patient communication

\section{Introduction}

White coat hypertension is a condition in which patients experience persistent high blood pressure levels when they are measured at a medical office or when a physician is present, but normal blood pressure levels during their daily lives and while in their home environment. ${ }^{1,2}$ Some authors use the terms "white coat effect," "white coat hypertension," and "white coat syndrome" interchangeably; others suggest "white coat hypertension" is preferred. According to the 2013 European Society of Hypertension/ Society of Cardiology guidelines, white coat hypertension characterizes individuals with office systolic/diastolic blood pressure measurements of 140/90 mmHg or higher on at least three occasions, with normal ambulatory or home blood pressure readings (24-hour ambulatory blood pressure $<130 / 80 \mathrm{mmHg}$ or a home blood pressure reading of 135/85 mmHg). ${ }^{3,4}$ On the other hand, the Eighth Joint National Committee in the United States maintains that hypertension should be treated pharmacologically in those individuals older than 60 years who have systolic/diastolic blood pressure measurements of $150 / 90 \mathrm{mmHg}$ or higher and those younger than 60 years with systolic/diastolic blood pressure measurements of $140 / 90 \mathrm{mmHg}$ or higher. ${ }^{5}$ However, because of the various numerical measurements used to diagnose white coat hypertension in the past literature, previous research has documented diverse effects on patient care and treatment. ${ }^{2}$ The failure to adequately diagnose white coat hypertension with standardized 
measurements has led to the inappropriate prescription and overuse of antihypertensive medications for individuals who are not persistently hypertensive. ${ }^{6}$ In this review, we provide the prevalence, etiology, and symptoms of white coat hypertension; discuss the consequences of persistent hypertension; and describe various methods for improving the patient-health care practitioner interaction and relationship to improve the accurate diagnosis and management of white coat hypertension.

\section{Prevalence and measurement}

Because of the varying measurements used between the office and home environment, doctors can mistakenly diagnose patients as hypertensive. Indeed, the prevalence of white coat hypertension has not been consistent across studies because of different blood pressure cut-offs used for normal out-of-office blood pressure readings and because of patients being inaccurately diagnosed with hypertension. ${ }^{2}$ The 2013 European guidelines report an overall prevalence of $13 \%{ }^{3}$ However, a recent review reported that $30 \%-40 \%$ of patients who are diagnosed with hypertension on the basis of their office blood pressure measurement alone have normal out-of-office blood pressure, according to ambulatory blood pressure measurements. ${ }^{2}$ Ambulatory monitoring may be the most effective method for diagnosing and confirming whether patients are persistently hypertensive or experiencing white coat syndrome. ${ }^{7,8}$ Ambulatory monitoring should be used to confirm the diagnosis of white coat hypertension within 3 months, and then every 6 months thereafter, as well as to provide continued monitoring of these patients, as there is a risk of developing true hypertension. ${ }^{9}$ In the clinical/office setting, measuring patient blood pressure in a quiet room with an automatic device may reduce the magnitude of the difference between office and out-of-office blood pressure measurements. ${ }^{10,11}$

Persistent hypertensive patients who have been unsuccessfully treated (resistant hypertensives) have been shown to demonstrate white coat hypertension as well. In a study of 497 outpatients who were being treated for hypertension, ambulatory blood pressure monitoring was conducted. Findings demonstrated that $63 \%$ of these patients were characterized as resistant hypertensives, whereas 37\% had a normal ambulatory blood pressure measurement and were experiencing white coat resistant hypertension. ${ }^{12}$ For this reason, it has been recommended that patients who start to have mildly or moderately high blood pressure measurements not be treated with medication unless there is targeted organ damage and their blood pressure remains high after three to six visits. ${ }^{11,13}$

\section{Patient profile for white coat hypertension}

Some research has shown that females, those older than 50 years, and nonsmokers are more likely to experience white coat hypertension. ${ }^{6,14-16}$ However, other research has shown that a patient's sex without associated confounding variables such as stress or anxiety does not determine whether one sex is more likely to develop white coat hypertension than the other. ${ }^{2}$ When determining predictors of white coat hypertension, research has shown that high perceived stress levels in women were associated with white coat hypertension more than in men. Women may experience a different stress response to clinic visits than men, as evidenced by their blood pressure measurements, and this might explain the high percentage of women experiencing white coat hypertension in previous research. ${ }^{17}$

The diagnosis of white coat hypertension has been shown to significantly increase with age. This could be a result of an age-related increase in arterial stiffness. ${ }^{2}$ Furthermore, patients with white coat hypertension also present fewer and lower office systolic blood pressure measurements. ${ }^{6,14,15}$

\section{Etiology}

White coat hypertension was first discovered by Riva-Rocci in 1896, who described this phenomenon as an increase in blood pressure experienced only during a physician's visit. This was not quantitatively researched until 1983, when researchers recorded intra-arterial blood pressure in hospitalized patients over the course of a 24-hour period. ${ }^{4,18}$ Researchers found that the appearance of a physician was accompanied by an immediate increase in a patient's blood pressure and heart rate. The patient's blood pressure peaked 2-4 minutes after the start of the visit and remained high throughout the duration of the physician's visit. ${ }^{2}$

One method of measuring and studying white coat hypertension has been with the use of microneurography, which measures the muscles and skin of the sympathetic nerve traffic. This is regulated by the reflexes in muscles and through emotional responses within the skin nerves. Results from a study researching white coat hypertension used this technique and found that pronounced activation of skin nerves and associated sympathetic inhibition of muscle nerve-traffic were demonstrated by participants when physicians either took blood pressure measurements or were present during these measurements. Researchers indicate that this response is similar to a "defense reaction" that has been demonstrated in animal models when they react to emotional stressors. Therefore, emotional factors such as anxiety or stress may 
be responsible for this microneurographic response and the origin of white coat hypertension. ${ }^{2,19}$ Patients with white coat hypertension have been shown to be more prone to higher levels of anxiety compared with both normotensive individuals and patients with persistent high blood pressure. ${ }^{20}$

This anxious emotional response may act as a mechanism in the development of white coat hypertension. However, research has also shown that patients who are prone to white coat hypertension do not hyperreact to all types of emotional stimuli. Instead, they only react to emotional stimuli that have been associated with a physician's office or the physician. ${ }^{21}$ This situational anxiety was further investigated in a study conducted by Ogedegbe et al. ${ }^{20}$ Findings from that research suggest that patients who experience white coat hypertension may have been classically conditioned to have high anxiety at physicians' offices as a result of negative or painful experiences with the medical office or physician. Consistent with past research, Ogedegbe et al found that when patients' blood pressure was measured by a physician, this resulted in a substantial increase in blood pressure compared with before the physician's entrance into the exam room. ${ }^{20}$ Therefore, where blood pressure is taken and by whom can have a significant effect on the reported measurement and the patient's emotional response; these factors can subsequently play a role in the development of white coat hypertension in patients. ${ }^{22}$

Furthermore, research has shown that those who expect to have a high blood pressure reading and/or are anxious about having a high blood pressure reading are more likely to have white coat hypertension. A study of 226 patients with normal and high blood pressure demonstrated this phenomenon. ${ }^{23}$ This study involved using a visual analog scale to assess anxiety at multiple instances during their office visit with the physician, rather than only before or after the office visit. Participants' blood pressure was measured using a 24-hour ambulatory blood pressure monitor and by a mercury column sphygmomanometer and stethoscope. Results from this study indicated that patients who had expectations of high blood pressure when being measured experienced elevated blood pressure. The researchers noted this could be caused by state or situational anxiety regarding the environment they are in or caused by an anxiety related to their expectations, rather than being caused by a persistent trait anxiety of the patients. ${ }^{23}$

The patient's perception of their blood pressure level has also been demonstrated to contribute to this situational anxious response. Labeling a patient as hypertensive solely on the basis of office readings can have a negative effect on their blood pressure levels, thus increasing their risk of demonstrating white coat hypertension in future office visits. This was demonstrated in a study conducted by Spruill et al, ${ }^{24}$ in which the authors found that of 214 participants, those who had a physician tell them they had high blood pressure in the past, regardless of whether they were truly hypertensive or not, were more likely to report greater anxiety during the office visit than those who perceived themselves as normotensive. Thus, white coat hypertension based on ambulatory measurements was demonstrated most clearly in participants who saw themselves as hypertensive during their office visit, regardless of whether their perceptions were medically correct. ${ }^{24}$

Therefore, both perception and the diagnosis by the physician play a major role in whether patients experience situational anxiety related to a medical setting and develop white coat hypertension. Researchers note there are two possible explanations that should be further researched. ${ }^{24}$ One possible explanation for this finding is that patients who receive a diagnosis of hypertension may adopt a "sick role," in which they try to find consistency between their symptoms and diagnosis. As a result, this could lead them to "cause" high levels of blood pressure via their anxiety when visiting the doctor. Another explanation for this finding could be that individuals who believe they are hypertensive may anticipate more negative information during their physician's visit and, as a result, could experience greater anxiety, thus demonstrating white coat hypertension. However, other factors such as stress or the anticipation of stressful news could also contribute to increased anxiety during an office visit and should be further studied. ${ }^{24}$

It is important to note the limitations of anxiety measurement in past studies. Situational anxiety has been measured by self-reports and interviewer measures, which can both be prone to bias. Therefore, further research is needed to better understand how situational anxiety plays a role in the white coat hypertension phenomenon.

Previous literature has also hypothesized that white coat hypertension is associated with metabolic syndrome. ${ }^{25}$ Metabolic syndrome is defined as an elevated risk for cardiovascular disease and diabetes. The demonstration of metabolic syndrome includes three of five physiologically abnormal symptoms such as obesity, high triglycerides, high-density lipoprotein, high blood pressure, and dysglycemia. ${ }^{26} \mathrm{~A}$ study following men aged 50 years and older for 20 years found that those who experienced white coat hypertension had a higher body mass index after a 20-year follow-up, higher triglycerides than normotensive men at the initial appointment, and higher plasma glucose than normotensive men. ${ }^{27}$ 
Other research has indicated participants who had white coat hypertension were more likely to develop diabetes than normotensives. ${ }^{28}$

\section{Consequences of patient anxiety and white coat hypertension}

It is important to consider the consequences of patient anxiety and white coat hypertension. There is evidence that white coat hypertension is associated with mild and severe physical health outcomes and an increased risk of developing sustained hypertension. ${ }^{29}$ Patients with white coat hypertension often progress to sustained hypertension. In a study following 1,412 patients who participated in the Pressioni Arteriose Monitorate E Loro Associazioni (PAMELA) study, $16.1 \%$ of patients had white coat hypertension at their initial examination. At their 10-year follow-up, $42.6 \%$ of those with white coat hypertension developed sustained hypertension. ${ }^{30}$ This could be a result of the physiological changes patients experience over time.

The physiological changes were investigated in a study conducted by Glen et al. ${ }^{31}$ Using identifiable markers of hypertensive cardiovascular disease, they examined whether individuals with white coat hypertension physiologically differed from patients with a diagnosis of persistent hypertension versus individuals with normal blood pressure. Sixty-five patients between the ages of 45 and 75 years who had no past history of a clinical disease such as cardiovascular or heart valve disease participated in this study. Blood pressure was taken with a semiautomatic oscillometric device without the presence of a physician or staff, and ambulatory blood pressure was measured for 28 hours with a device recording blood pressure every 15 minutes during the day and every 20 minutes during the night. Diastolic function was measured by a pulsed-wave Doppler. Results from this study indicated similar abnormalities in cardiovascular function in patients with white coat hypertension and in those with a diagnosis of hypertension. Both groups presented with larger arteries and diastolic left ventricular abnormal function, and they also demonstrated similar abnormalities of stiffness and elasticity of the large arteries compared with individuals with no known past history of hypertension. Patients with white coat hypertension demonstrated functional cardiovascular abnormalities without identifiable structural abnormalities. Thus, these markers increased the risk for a future diagnosis of sustained hypertension for participants who exhibited white coat hypertension. The researchers noted these functional abnormalities can be reversed by antihypertensive treatment. Therefore, early intervention is important and will hinder the progression of hypertension in patients with white coat hypertension. This early detection would also decrease the development of cardiovascular disease, functional abnormalities such as microalbuminuria, and target organ damage, which have been associated with white coat hypertension. ${ }^{31}$

A recent meta-analytic review of ten studies reported that carotid atherosclerosis was significantly greater in patients with white coat hypertension compared to those without hypertension. ${ }^{32}$ This targeted organ damage was also recently found in a review conducted by Martin and McGrath. ${ }^{29}$ This review consisted of ten previous studies measuring target organ damage that used left ventricular mass as their measure of organ damage. Six of these studies found an increase in left ventricular mass in those who experienced white coat syndrome compared with normotensive patients. In addition, a meta-analysis of 25 studies reported a similar effect of increased left ventricular mass for those with white coat syndrome. ${ }^{33}$

The consequences of experiencing this physiological change along with situational anxiety can also have a negative effect on the patient's quality of life. Although these negative effects have not been researched in patients with white coat hypertension, hypertension has been extensively researched in terms of its effect on optimal health, quality of life, and adherence to medication. Although those with white coat hypertension do not exhibit the consistent diagnostic measures of persistent hypertension, they are at an increased risk of developing persistent hypertension as their age progresses and without hypertensive treatment, as discussed by Mancia et al. ${ }^{30}$

Research has indicated that awareness of hypertension is associated with poor health-related quality of life. In a study of 497 Finnish patients, those who were aware of their diagnosis demonstrated lower scores in physical functioning and general health than patients who were unaware of their hypertension. This awareness could lead to a lower quality of life and lower satisfaction with life. However, the researchers noted this could have been a result of the adverse effects of their antihypertensive medication, with $47 \%$ of the participants taking at least one high blood pressure medication and 34\% taking three medications. ${ }^{34}$ These results have also been found in 519 patients who were asked to self-assess their well-being. Those diagnosed with hypertension had significantly lower general health-status scores compared with normotensives and were more likely to be receiving more than one medication. ${ }^{35}$ Therefore, patients who are aware of their diagnosis and are being treated with more than one antihypertensive medication are more likely to report a lower quality of life. 
Inadequate control of persistent hypertension has been shown to be associated with low medication adherence, possibly as a result of the medication's adverse effects. Nonadherence has negative consequences on disease progression and outcomes; it is estimated that half of the patients diagnosed with hypertension do not adhere to their prescribed medications, and fewer than one in three patients have controlled blood pressure. ${ }^{36} \mathrm{~A}$ review by Kjellgren et $\mathrm{a}{ }^{37}$ reported that a patient's lack of knowledge about the provider-patient decision-making process regarding prescribing antihypertension medication can contribute to nonadherence to the treatment plan. Therefore, communication and collaboration between the patient and their health care provider is a critical factor in both adherence to their treatment regimen and optimal health. ${ }^{37}$ As a result, improving communication between the patient and their health care provider is crucial in maintaining and improving their health.

\section{Improving the patient-health care professional relationship through communication, empathy, and trust}

White coat hypertension may be addressed through the development of a therapeutic relationship between physician and patient. Effective communication and relationship building can reduce the patient's anxiety about their illness and about their interaction with a physician. This is not to imply that talking more before obtaining blood pressure readings will reduce blood pressure but, instead, that physicians' overall attention to effective communication and empathy may increase trust and reduce the patient's anxiety, which can contribute to white coat hypertension.

Communication between physicians and patients is often considered a cornerstone of good medical care. Effective physician-patient communication has two primary functions: instrumental exchange and affective communication. ${ }^{38,39}$ Instrumental exchange is focused on the tasks of the medical visit, the process of information exchange, and the discussion of biomedical issues. Affective communication is focused on developing a therapeutic relationship, asking open-ended questions, discussing the patient's psychosocial issues, and expressing empathy. This aspect of communication is sometimes referred to as "bedside manner" or "relational communication." Verbal and nonverbal communication fit into these categories, as a physician can deliver affective communication through nonverbal behaviors such as warm voice tone, appropriate eye contact, a reassuring touch on the arm, or a kind facial expression, for example. Although verbal communication has received more attention than nonverbal communication in both physician communication skills training programs and physician-patient communication research, nonverbal communication plays an important complementary role and does have effects on patient outcomes. For instance, Henry et a ${ }^{40}$ demonstrated that warmth, positivity, and active listening, all of which were displayed nonverbally, were significantly associated with improved patient satisfaction. There is also increasing emphasis on patient-centered communication, in which the physician treats the patient as a whole person and strives to understand the patient's perspective and beliefs about their illness and treatment. ${ }^{41,42} \mathrm{An}$ association has been found, for example, between patient perceptions of physician patient-centered communication and greater levels of patient recovery from discomfort and concern after their medical visit. ${ }^{43}$ Research indicates that both affective and instrumental communication are predictive of patient outcomes such as patient satisfaction, ${ }^{44}$ patient adherence, ${ }^{45}$ and health-related outcomes. ${ }^{46,47}$

Other areas of physician-patient communication that can be addressed to attempt to reduce patient anxiety and potentially reduce white coat hypertension are empathy and trust. Empathy involves understanding the patient's feelings and experience and communicating that understanding to the patient. ${ }^{48}$ It involves affective, cognitive, and communicative components. Physicians practicing empathy may engage in behaviors such as eliciting patient feelings or concerns, reflecting those concerns back to the patient, and actively listening to the patient. The physician's empathy has been found to be related to patient outcomes, such as patient adherence and patient satisfaction. For example, a recent review examined seven studies that correlated physician empathy with various outcomes and reported a significant relationship between physician empathy and lower patient anxiety levels. ${ }^{49}$ Compassion is a quality similar to empathy. One study showed patients a videotape of a physician showing high levels of compassion..$^{50}$ Participants who saw the "high compassion" video felt significantly less anxious after viewing it.

Studies have shown that physicians can improve their empathy through training in communication skills. For example, one study of training in communication skills for primary care physicians revealed a $37 \%$ increase in ratings of physician empathy from baseline to follow-up. ${ }^{51} \mathrm{~A}$ study examining the effects of a 3-day course in communication skills for oncologists demonstrated a significant increase in videotaped expressions of empathy in those physicians who took the course. ${ }^{52}$ In such courses, physicians are trained in communication skills through role play, videotape review of 
medical visits, and group discussion, among other techniques. Training courses can be particularly helpful for more experienced physicians, in addition to residents and those at earlier stages of their medical careers. ${ }^{53}$

Trust in one's physician may also play a significant role in reducing anxiety during an office visit. A key component of the development of trust is forming a caring, respectful relationship with patients through good communication, sharing in decision-making, and providing good technical care and correct treatment. ${ }^{54}$ One way trust may be achieved is by having adequate time to spend with patients, as patients may feel more anxious when their physician is rushed or hurrying. Some recent evidence indicates the average length of a primary care office visit is 15 minutes,${ }^{55}$ and time constraints may have effects on the physician-patient relationship. For example, listening to the patient's concerns, understanding the patient's perspective regarding their illness and treatment, and answering patient questions all take time, and when these actions are combined with the other tasks of the medical visit, time pressures can be a constraint for both the physician and patient.

\section{Training in communication skills}

Extensive theoretical and empirical literature has addressed the issue of improving communication between medical providers and patients, ${ }^{56-58}$ and training programs and courses in communication skills have grown in recent years. Most medical schools now involve coursework in communication and interpersonal skills, and training programs are also conducted at other levels, such as in residency programs and with practicing physicians. However, most who work in the area would agree that such training is still fairly limited. ${ }^{59}$ Often, physicians are trained and practice skills through role-play activities, via analysis of videotapes of medical interactions, and through the development of techniques they can use in their own practice. A recent review of interventions to improve physician-patient communication examined 15 studies of the effects of communication interventions on cardiovascular disease outcomes. ${ }^{60}$ Only four of the studies reported a significant effect of communication skills intervention on clinical cardiovascular-related outcomes, highlighting the need to make methodological improvements in future studies assessing the relationship between communication and health outcomes.

Because central components of white coat hypertension include anxiety and emotional distress, it is useful to examine studies of interventions to improve communication skills that focus on emotional outcomes. Roter et $\mathrm{al}^{61}$ randomized physicians to an 8-hour training program focused on defining patients' emotional concerns and responding to those emotions. Results indicated that the trained physicians made a stronger effort to treat emotional concerns of patients, and patients subsequently showed reduced emotional distress up to 6 months later. Another study with cancer patients focused on the effects of physician communication skills training on patient anxiety after a medical visit. ${ }^{62}$ These authors found that supportive communication and asking questions designed to elicit other concerns that had not been addressed were correlated with reduced anxiety.

Another aspect of communication skills training is training for patients. Often, such training programs involve improving patient participation and involvement in care through such techniques as question asking or coaching before their medical visit. ${ }^{63}$ One intervention involved patients preparing before the medical visit by listing questions to ask their physician; patients who listed and asked questions reported being less anxious. ${ }^{64}$ Researchers of another study of men newly diagnosed with prostate cancer attempted to increase their selfefficacy by giving them information and a list of questions to ask before their physician visit. ${ }^{65}$ Results indicated that men who received this intervention had significantly lower state anxiety 6 weeks later. Improving information-giving and exchange between providers and patients may be an important avenue to reduce patient anxiety and fear, as patients become more focused on providing and seeking information. Patient training programs have a positive effect on outcomes, such as adherence to treatment, as demonstrated in a study involving asking patients to complete a communication training booklet before their appointment. ${ }^{66}$ Findings of this study revealed better adherence to medication, behavior change, and appointment keeping in patients who were trained.

\section{Future directions of the patient- health care professional relationship}

There may be other techniques that can, in the future, enhance the provider-patient relationship, and thereby reduce patient anxiety and white coat hypertension. Ideally, the utilized techniques should focus on providing information and reducing stress before office visits. Some past interventions to improve patient communication, for example, have involved waiting room interventions to improve communication about pain by using health educators ${ }^{67}$ and increasing patient-initiated communication through having health educators coach participants to ask questions and to express concerns. ${ }^{68}$ Interventions using health educators might be useful in working with patients to reduce stress and anxiety before medical visits. 
Telemedicine presents another alternative for changing the physician-patient relationship to reduce white coat hypertension and anxiety. There are many methods of telemedicine, such as email communication and interactive video medical visits, that could be used to change the typical communication process and potentially reduce anxiety. There is evidence that patient-centered communication and patient involvement in care can still occur in telemedicine at the same level as they do in face-to-face interactions. ${ }^{69}$ Studies show that patient satisfaction can be achieved through this form of medical care, but much more research in this area is needed..$^{70}$

When using telemedicine for hypertension care, studies have shown the potential to improve the accurate diagnosis of essential hypertension as well. The telemedicine service consists of using an automatic home blood pressure monitor connected to a landline telephone to transmit the data. The blood pressure readings are then transmitted to the patient's physician. Results from this study indicated that $64 \%$ of patients using this service were diagnosed with essential hypertension, whereas only $26 \%$ of patients not using this service were correctly diagnosed with hypertension. Furthermore, those in the telemedicine service group were able to have a diagnosis earlier than those not using this service. ${ }^{71}$ Not only are patients able to be diagnosed earlier in the illness's progression, but past research has also demonstrated that the use of telemedicine can improve medication adherence and blood pressure control, along with improving health outcomes, thereby possibly also reducing the use of health care services and associated costs..$^{72}$ Although this use of technology has not been studied in patients with white coat hypertension, the results and implications of these previous studies could have beneficial effects on these patients, leading to a greater likelihood of optimal health.

\section{Conclusion}

White coat hypertension is a common medical problem in which a patient presents high blood pressure levels in the physician's office, yet the readings return to normal levels when the patient is in their typical environment. Because of this condition, many patients may be misdiagnosed and unnecessarily treated for persistent hypertension. White coat hypertension may be caused by increased anxiety while at the physician's office and/or in the presence of the physician. There is evidence that negative health outcomes, such as target organ damage, are associated with white coat hypertension. In addition, over time, white coat hypertension can progress to sustained hypertension. Changing the typical protocol for office blood pressure measurement is recommended, although it is also useful to attempt to reduce the common issue of patient anxiety. Improving interactions and communication between a patient and their health care provider can decrease a patient's anxiety, which can also decrease a patient's likelihood of developing white coat hypertension. Training health care providers to improve communication by actively listening to the patient and by including the patient in the decision-making process has been shown to effectively decrease patient anxiety, along with improving treatment adherence. Likewise, training patients to ask questions and express concerns can also increase communication between the patient and the physician. Improving patient and health care provider interaction through effective communication, empathy, and trust can reduce anxiety and lessen the negative effects associated with white coat hypertension. As illustrated by the idea of common factors theory, any interventions to improve communication skills are grounded in the common ideas of empathy, collaboration, and the therapeutic alliance. ${ }^{73}$ Thus, efforts to improve provider-patient communication and reduce patient anxiety should be based in these underlying general principles.

\section{Disclosure}

KHZ reports receiving speaking fees from Merck. The authors report no other conflicts of interest in this work.

\section{References}

1. Celis H, Fagard RH. White-coat hypertension: a clinical review. Eur J Intern Med. 2004;15(6):348-357.

2. Mancia G, Bombelli M, Seravalle G, Grassi G. Diagnosis and management of patients with white-coat and masked hypertension. Nat Rev Cardiol. 2011;8(12):686-693.

3. Mancia G, Fagard R, Narkiewicz K, et al. 2013 ESH/ESC guidelines for the management of arterial hypertension: the Task Force for the Management of Arterial Hypertension of the European Society of Hypertension (ESH) and of the European Society of Cardiology (ESC). Eur Heart J. 2013;34(28):2159-2219.

4. Sipahioglu NT, Sipahioglu F. Closer look at white-coat hypertension. World J Methodol. 2014;4(3):144-150.

5. James PA, Oparil S, Carter BL, et al. 2014 evidence-based guideline for the management of high blood pressure in adults: report from the panel members appointed to the Eighth Joint National Committee (JNC 8). JAMA. 2014;311(5):507-520.

6. Dolan E, Stanton A, Atkins N, et al. Determinants of white-coat hypertension. Blood Press Monit. 2004;9(6):307-309.

7. Franklin SS, Thijs L, Hansen TW, O’Brien E, Staessen JA. White-coat hypertension: new insights from recent studies. Hypertension. 2013; 62(6):982-987.

8. Boggia J, Hansen T, Asayama K, Luzardo L, Li Y, Staessen J. White-coat Hypertension on Automated Blood Pressure Measurement Implications for Clinical Practice. Eur J Cardiovasc Med. 2011;1:17-21.

9. Grossman E. Ambulatory blood pressure monitoring in the diagnosis and management of hypertension. Diabetes Care. 2013;36(Suppl 2): S307-S311. 
10. Pickering TG, Hall JE, Appel LJ, et al. Recommendations for blood pressure measurement in humans and experimental animals: part 1: blood pressure measurement in humans: a statement for professionals from the Subcommittee of Professional and Public Education of the American Heart Association Council on High Blood Pressure Research. Circulation. 2005;111(5):697-716.

11. Myers MG, Valdivieso MA. Use of an automated blood pressure recording device, the BpTRU, to reduce the "white coat effect" in routine practice. Am J Hypertens. 2003;16(6):494-497.

12. Muxfeldt ES, Bloch KV, Nogueira AR, Salles GF. True resistant hypertension: is it possible to be recognized in the office? Am J Hypertens. 2005;18(12 Pt 1):1534-1540.

13. Cohen DL, Townsend RR. How significant is white coat hypertension? J Clin Hypertens (Greenwich). 2010;12(8):625-626.

14. Fisher M, Blackwell J, Saseen J. What is the best way to identify patients with white-coat hypertension? J Fam Pract. 2005;54(6): $549-550$

15. Verdecchia P, Palatini P, Schillaci G, Mormino P, Porcellati C, Pessina AC. Independent predictors of isolated clinic ('white-coat') hypertension. J Hypertens. 2001;19(6):1015-1020.

16. Manios ED, Koroboki EA, Tsivgoulis GK, et al. Factors influencing white-coat effect. Am J Hypertens. 2008;21(2):153-158.

17. MacDonald MB, Laing GP, Wilson MP, Wilson TW. Prevalence and predictors of white-coat response in patients with treated hypertension. CMAJ. 1999;161(3):265-269.

18. Mancia G, Bertinieri G, Grassi G, et al. Effects of blood-pressure measurement by the doctor on patient's blood pressure and heart rate. Lancet. 1983;2(8352):695-698.

19. Grassi G, Turri C, Vailati S, Dell'Oro R, Mancia G. Muscle and skin sympathetic nerve traffic during the "white-coat" effect. Circulation. 1999;100(3):222-225.

20. Ogedegbe G, Pickering TG, Clemow L, et al. The misdiagnosis of hypertension: the role of patient anxiety. Arch Intern Med. 2008; 168(22):2459-2465.

21. Parati G, Pomidossi G, Casadei R, et al. Comparison of the cardiovascular effects of different laboratory stressors and their relationship with blood pressure variability. J Hypertens. 1988;6(6):481-488.

22. Gerin W, Marion RM, Friedman R, James GD, Bovbjerg DH, Pickering TG. How should we measure blood pressure in the doctor's office? Blood Press Monit. 2001;6(5):257-262.

23. Jhalani J, Goyal T, Clemow L, Schwartz JE, Pickering TG, Gerin W. Anxiety and outcome expectations predict the white-coat effect. Blood Press Monit. 2005;10(6):317-319.

24. Spruill TM, Pickering TG, Schwartz JE, et al. The impact of perceived hypertension status on anxiety and the white coat effect. Ann Behav Med. 2007;34(1):1-9.

25. Helvaci MR, Sevinc A, Camci C, Yalcin A. Treatment of white coat hypertension with metformin. Int Heart J. 2008;49(6):671-679.

26. Alberti KG, Eckel RH, Grundy SM, et al; International Diabetes Federation Task Force on Epidemiology and Prevention; Hational Heart, Lung, and Blood Institute; American Heart Association; World Heart Federation; International Atherosclerosis Society; International Association for the Study of Obesity. Harmonizing the metabolic syndrome: a joint interim statement of the International Diabetes Federation Task Force on Epidemiology and Prevention; National Heart, Lung, and Blood Institute; American Heart Association; World Heart Federation; International Atherosclerosis Society; and International Association for the Study of Obesity. Circulation. 2009;120(16):1640-1645.

27. Björklund K, Lind L, Vessby B, Andrén B, Lithell H. Different metabolic predictors of white-coat and sustained hypertension over a 20-year follow-up period: a population-based study of elderly men. Circulation. 2002;106(1):63-68.

28. Hosaka M, Mimura A, Asayama K, et al. Relationship of dysregulation of glucose metabolism with white-coat hypertension: the Ohasama study. Hypertens Res. 2010;33(9):937-943.

29. Martin CA, McGrath BP. White-coat hypertension. Clin Exp Pharmacol Physiol. 2014;41(1):22-29.
30. Mancia G, Bombelli M, Facchetti R, et al. Long-term risk of sustained hypertension in white-coat or masked hypertension. Hypertension. 2009;54(2):226-232.

31. Glen SK, Elliott HL, Curzio JL, Lees KR, Reid JL. White-coat hypertension as a cause of cardiovascular dysfunction. Lancet. 1996;348(9028): 654-657.

32. Cuspidi C, Sala C, Tadic M, Rescaldani M, Grassi G, Mancia G. Is white-coat hypertension a risk factor for carotid atherosclerosis? A review and meta-analysis. Blood Press Monit. 2015 Apr;20(2):57-63.

33. Cuspidi C, Rescaldani M, Tadic M, Sala C, Grassi G, Mancia G. Whitecoat hypertension, as defined by ambulatory blood pressure monitoring, and subclinical cardiac organ damage: a meta-analysis. $J$ Hypertens. 2015;33(1):24-32.

34. Korhonen PE, Kivelä S-L, Kautiainen H, Järvenpää S, Kantola I. Healthrelated quality of life and awareness of hypertension. J Hypertens. 2011;29(11):2070-2074.

35. Lawrence WF, Fryback DG, Martin PA, Klein R, Klein BE. Health status and hypertension: a population-based study. J Clin Epidemiol. 1996;49(11):1239-1245.

36. Krousel-Wood M, Thomas S, Muntner P, Morisky D. Medication adherence: a key factor in achieving blood pressure control and good clinical outcomes in hypertensive patients. Curr Opin Cardiol. 2004; 19(4):357-362.

37. Kjellgren KI, Ahlner J, Säljö R. Taking antihypertensive medication - controlling or co-operating with patients? Int $J$ Cardiol. 1995;47(3):257-268.

38. Ong LM, de Haes JC, Hoos AM, Lammes FB. Doctor-patient communication: a review of the literature. Soc Sci Med. 1995;40(7):903-918.

39. Bensing JM, Dronkers J. Instrumental and affective aspects of physician behavior. Med Care. 1992;30(4):283-298.

40. Henry SG, Fuhrel-Forbis A, Rogers MA, Eggly S. Association between nonverbal communication during clinical interactions and outcomes: a systematic review and meta-analysis. Patient Educ Couns. 2012;86(3):297-315.

41. Stewart MA. What is a successful doctor-patient interview? A study of interactions and outcomes. Soc Sci Med. 1984;19(2):167-175.

42. Platt FW, Gaspar DL, Coulehan JL, et al. "Tell me about yourself": the patient-centered interview. Ann Intern Med. 2001;134(11): 1079-1085.

43. Stewart M, Brown JB, Donner A, et al. The impact of patient-centered care on outcomes. J Fam Pract. 2000;49(9):796-804.

44. Williams S, Weinman J, Dale J. Doctor-patient communication and patient satisfaction: a review. Fam Pract. 1998;15(5):480-492.

45. Zolnierek KB, Dimatteo MR. Physician communication and patient adherence to treatment: a meta-analysis. Med Care. 2009;47(8): 826-834.

46. Stewart MA. Effective physician-patient communication and health outcomes: a review. CMAJ. 1995;152(9):1423-1433.

47. Kaplan SH, Greenfield S, Ware JE Jr. Assessing the effects of physicianpatient interactions on the outcomes of chronic disease. Med Care. 1989;27(3)(Suppl):S110-S127.

48. Coulehan JL, Platt FW, Egener B, et al. "Let me see if i have this right ...": words that help build empathy. Ann Intern Med. 2001;135(3): 221-227.

49. Derksen F, Bensing J, Lagro-Janssen A. Effectiveness of empathy in general practice: a systematic review. Br J Gen Pract. 2013;63(606): e76-e84.

50. Fogarty LA, Curbow BA, Wingard JR, McDonnell K, Somerfield MR. Can 40 seconds of compassion reduce patient anxiety? J Clin Oncol. 1999;17(1):371-379.

51. Bonvicini KA, Perlin MJ, Bylund CL, Carroll G, Rouse RA, Goldstein MG. Impact of communication training on physician expression of empathy in patient encounters. Patient Educ Couns. 2009;75(1): $3-10$.

52. Jenkins V, Fallowfield L. Can communication skills training alter physicians' beliefs and behavior in clinics? J Clin Oncol. 2002;20(3): 765-769. 
53. Fallowfield L, Jenkins V, Farewell V, Saul J, Duffy A, Eves R. Efficacy of a Cancer Research UK communication skills training model for oncologists: a randomised controlled trial. Lancet. 2002;359(9307):650-656.

54. Thom DH, Campbell B. Patient-physician trust: an exploratory study. J Fam Pract. 1997;44(2):169-176.

55. Tai-Seale M, McGuire TG, Zhang W. Time allocation in primary care office visits. Health Serv Res. 2007;42(5):1871-1894.

56. Haskard KB, Williams SL, DiMatteo MR, Rosenthal R, White MK, Goldstein MG. Physician and patient communication training in primary care: effects on participation and satisfaction. Health Psychol. 2008;27(5):513-522

57. Rao JK, Anderson LA, Inui TS, Frankel RM. Communication interventions make a difference in conversations between physicians and patients: a systematic review of the evidence. Med Care. 2007;45(4): 340-349.

58. Cegala DJ, Lenzmeier Broz S. Physician communication skills training: a review of theoretical backgrounds, objectives and skills. Med Educ. 2002;36(11):1004-1016.

59. Levinson W, Lesser CS, Epstein RM. Developing physician communication skills for patient-centered care. Health Aff (Millwood). 2010;29(7):1310-1318.

60. Schoenthaler A, Kalet A, Nicholson J, Lipkin M Jr. Does improving patient-practitioner communication improve clinical outcomes in patients with cardiovascular diseases? A systematic review of the evidence. Patient Educ Couns. 2014;96(1):3-12.

61. Roter DL, Hall JA, Kern DE, Barker LR, Cole KA, Roca RP. Improving physicians' interviewing skills and reducing patients' emotional distress. A randomized clinical trial. Arch Intern Med. 1995;155(17): 1877-1884.

62. Liénard A, Merckaert I, Libert Y, et al. Factors that influence cancer patients' anxiety following a medical consultation: impact of a communication skills training programme for physicians. Ann Oncol. 2006;17(9):1450-1458.
63. Harrington J, Noble LM, Newman SP. Improving patients' communication with doctors: a systematic review of intervention studies. Patient Educ Couns. 2004;52(1):7-16.

64. Thompson SC, Nanni C, Schwankovsky L. Patient-oriented interventions to improve communication in a medical office visit. Health Psychol. 1990;9(4):390-404.

65. Davison BJ, Degner LF. Empowerment of men newly diagnosed with prostate cancer. Cancer Nurs. 1997;20(3):187-196.

66. Cegala DJ, Marinelli T, Post D. The effects of patient communication skills training on compliance. Arch Fam Med. 2000;9(1):57-64.

67. Street RL Jr, Slee C, Kalauokalani DK, Dean DE, Tancredi DJ, Kravitz RL. Improving physician-patient communication about cancer pain with a tailored education-coaching intervention. Patient Educ Couns. 2010;80(1):42-47.

68. Kim YM, Putjuk F, Basuki E, Kols A. Increasing patient participation in reproductive health consultations: an evaluation of "Smart Patient" coaching in Indonesia. Patient Educ Couns. 2003;50(2):113-122.

69. Agha Z, Schapira RM, Laud PW, McNutt G, Roter DL. Patient satisfaction with physician-patient communication during telemedicine. Telemed J E Health. 2009;15(9):830-839.

70. Mair F, Whitten P. Systematic review of studies of patient satisfaction with telemedicine. BMJ. 2000;320(7248):1517-1520.

71. Rogers MA, Buchan DA, Small D, Stewart CM, Krenzer BE. Telemedicine improves diagnosis of essential hypertension compared with usual care. J Telemed Telecare. 2002;8(6):344-349.

72. Friedman RH, Kazis LE, Jette A, et al. A telecommunications system for monitoring and counseling patients with hypertension. Impact on medication adherence and blood pressure control. Am J Hypertens. 1996;9(4 Pt 1):285-292.

73. Laska KM, Gurman AS, Wampold BE. Expanding the lens of evidencebased practice in psychotherapy: a common factors perspective. Psychotherapy (Chic). 2014;51(4):467-481.
Psychology Research and Behavior Management

\section{Publish your work in this journal}

Psychology Research and Behavior Management is an international, peerreviewed, open access journal focusing on the science of psychology and its application in behavior management to develop improved outcomes in the clinical, educational, sports and business arenas. Specific topics covered include: Neuroscience, memory \& decision making; Behavior

\section{Dovepress}

modification \& management; Clinical applications; Business \& sports performance management; Social and developmental studies; Animal studies. The manuscript management system is completely online and includes a quick and fair peer-review system. Visit http://www.dovepress. com/testimonials.php to read real quotes from published authors. 